\title{
АНАЛИЗ МАРКЕТИНГОВЫХ ИССЛЕДОВАНИЙ ВОЗМОЖНОСТЕЙ РАЗВИТИЯ БИЗНЕСА В ИМЕРЕТИНСКОМ РЕГИОНЕ (НА ПРИМЕРЕ ПРОДОВОЛЬСТВЕННОЙ ПРОДУКЦИИ, ПРОИЗВОДИМОЙ В ИМЕРЕТИ)
}

\author{
Каркашадзе Н. Б., д.э.н., ассочииированный профессор \\ 2. Кутаиси, Грузия, Кутаисский государственньй университет имени Акакия Церетели
}

DOI: https://doi.org/ 10.31435/rsglobal_ws/30122018/6273

\section{ARTICLE INFO}

Received: 18 October 2018

Accepted: 18 December 2018

Published: 30 December 2018

\section{KEYWORDS}

Economic growth of the country, competitiveness,

business development potential, marketing researches.

\begin{abstract}
The article focuses on the business development in regions and its promotion. Concerning these problems, in the article the results of the survey, conducted in three regions, in particular in Kutaisi, Batumi and Zaporozhye are given, from which it is obvious, that the region has the potential of making its products known and demanded on both, domestic and international markets. The following recommendations are given:

- To organize open door day, where the products produced in the Imereti region will be presented, according to the commodity groups and producers of business.

- To arrange meetings on the issues related to business subjects and hotel managers' proposals and their requirements.

- Promotional leaflets and sheets of each commodity category will be produced for a separate business entity in order to create a competitive environment that will allow users to get acquainted with each category and choose products that are acceptable to them according to useful properties, price and other indicators.

Consideration of these recommendations will help business entrepreneurs to get success.
\end{abstract}

Citation: Каркашадзе Н. Б. (2018) Analiz Marketingovih Issledovanii Vozmojnostei Razvitiya Biznesa v Imeretinskom Regione (na Primere Prodovolstvennoi Produkcii, Proizvodimoi v Imereti). World Science. 12(40), Vol.2. doi: 10.31435/rsglobal_ws/30122018/6273

Copyright: (C) 2018 Каркашадзе Н. Б. This is an open-access article distributed under the terms of the Creative Commons Attribution License (CC BY). The use, distribution or reproduction in other forums is permitted, provided the original author(s) or licensor are credited and that the original publication in this journal is cited, in accordance with accepted academic practice. No use, distribution or reproduction is permitted which does not comply with these terms.

\section{Введение.}

Переход на рыночные отношения является сложным и тяжелым процессом для каждого предприятия, организации, региона и страны. Он требует мобилизации всех сил и средств предприятия, страны для достижения конкурентного преимущества в глобальной среде. Для этого одной из основных целей является обеспечение экономического роста страны, который зависит от роста макро- и микроэкономических показателей страны, что прямо связано с включением страны в международные отношения с маркетинговой точки зрения.

Одним из важных факторов конкурентоспособности Грузии является возрождение отечественного производства и создание благоприятной среды для бизнеса. Для этого необходимо провести маркетинговые исследования как на уровне страны, так и региона для изучения потенциальных возможностей, анализ результатов которых даст ясное представление о существующих на рынке потребностях как внутри страны, так и за ее пределами. Указанная информация поможет субъектам бизнеса предложить произведенную в регионе продукцию тому целевому рынку, который будет эффективен для их последующих успехов. Особого внимания требует поощрение производства экспортной продукции с льготными кредитами. 
Результаты исследования. Известно, что правительство Грузии осуществляет множество мероприятий для поддержки малого и среднего бизнеса и для улучшения социального положения региона, но еще больше необходимо сделать, так как по простоте ведения бизнеса мы пока еще находимся на 8-м месте. Вместе с тем необходимо выявить причины, мешающие развитию бизнеса, которые существуют в Имеретинском регионе и которые тормозят деятельность субъектов бизнеса. Целью нашего исследования является именно изучение потенциала развития бизнеса в Имеретинском регионе для того, чтобы установить насколько известна и потребляема произведенная в Имеретинском регионе продукция.

Объектом исследования была выбрана сеть гостиниц как в Имеретинском регионе (Кутаиси), так и в Аджарии, в частности в Батуми и сеть гостиниц в Украинском городе Запорожье.

При исследовании был использован полевой метод, который учитывает количественный метод с помощью опроса, в котором участвовали 20 гостиничных объектов Кутаиси, 40 гостиничных объектов Батуми и 21 гостиничных объекта Запорожья. Предметом исследования являлось установление потребности на произведенную в Имеретинском регионе продукцию (продовольственную).

В Кутаиси и Батуми предметом исследования являлось установление как уровня известности, так и уровня потребности на продукцию (12 названий), произведенную в Имерети. Исследование показало, что в Кутаиси $100 \%$ потребность: на помидоры, сыр, зелень, яйца и кур, а 90-95\% на огурцы. Вместе с тем на минеральную воду «Саирме»- 65\%, вино «Хареба»$63,2 \%$, сухофрукты - $60 \%$, чурчхелу $-65 \%$. В Аджарской автономной республике, в Частности в Батуми по проведенным исследованиям желание приобрести продукцию, произведенную в Имерети, по товарным категория распределилось таким образом: на огурцы, помидоры, яйца и куры - 90\%, зелень - 97,5\%, сыр - 95\%, чай - $86 \%$, чурчхелу $-75 \%$, сухофрукты и мёд $-67 \%$, минеральную воду «Саирмие» - 60\%, а также вино «Хареба»- $53 \%$.

На Украине, в частности в результате проведенного исследования в Запорожском регионе, которое было проведено в 21 гостинице, Желание приобрести произведенную в Имерети продукцию по товарным категориям высказали: на зелень - 57\%, минеральную воду «Саирме» - 38\%, вино «хареба» - 43\% мёд - 24\%, чай - 29\%, чурчхелу - 48\%, (см. диаграммы $1,2,3,4)[1]$.

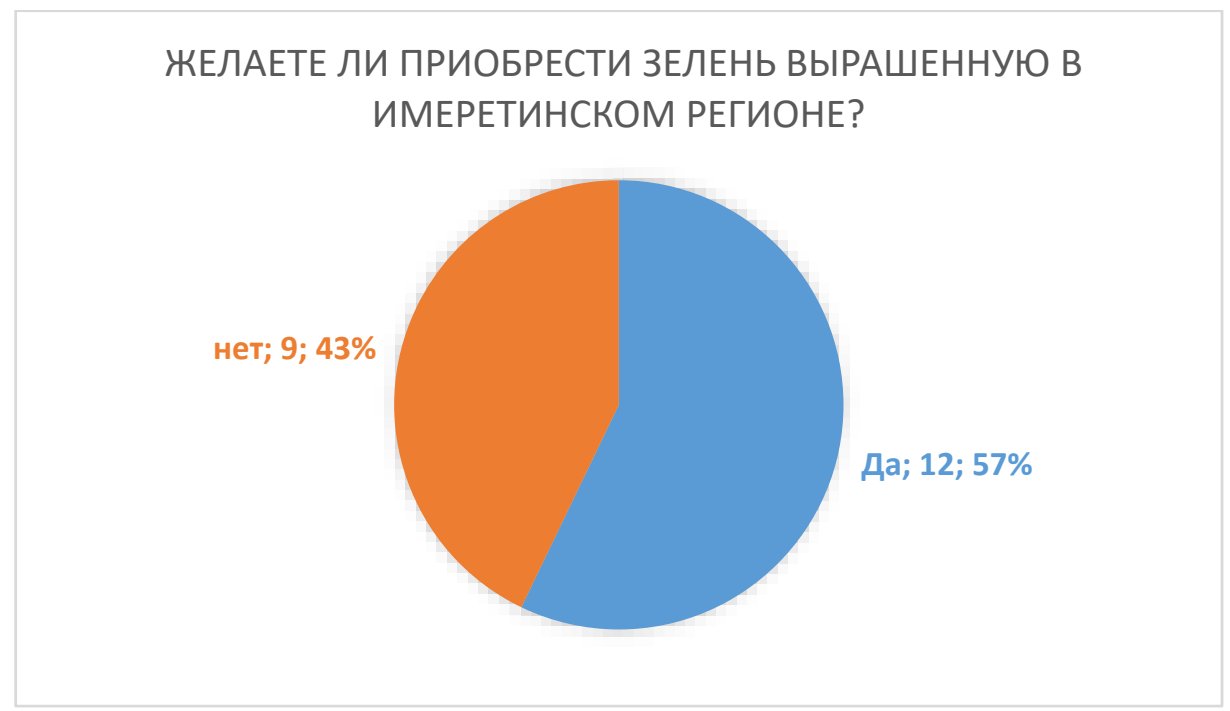

Диаграмма 1. 
ЖЕЛАЕТЕ ЛИ ПРИОБРЕСТИ МИНЕРАЛЬНУЮ ВОДУ

"САИРМЕ"?

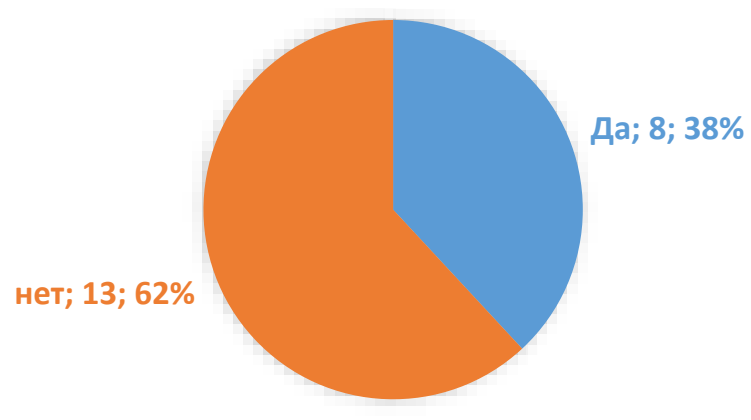

Диаграмма 2.

ЖЕЛАЕТЕ ЛИ ПРИОБРЕСТИ ВИНО (БЕЛОЕ, КРАСНОЕ), ПРОИЗВЕДЕННОЕ В ИМЕРЕТИНСКОМ РЕГИОНЕ КОМПАНИЕЙ "ХАРЕБА"?

да; 9; $43 \%$

нет; $12 ; 57 \%$

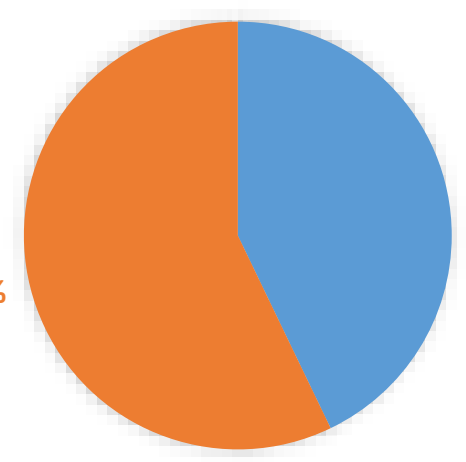

Диаграмма 3.

ЖЕЛАЕТЕ ЛИ ПРИОБРЕСТИ СУХОФРУКТЫ, ПРИЗВЕДЁННЫЕ В ИМЕРЕТИНСКОМ РЕГИОНЕ (ГРУЗИЯ)?

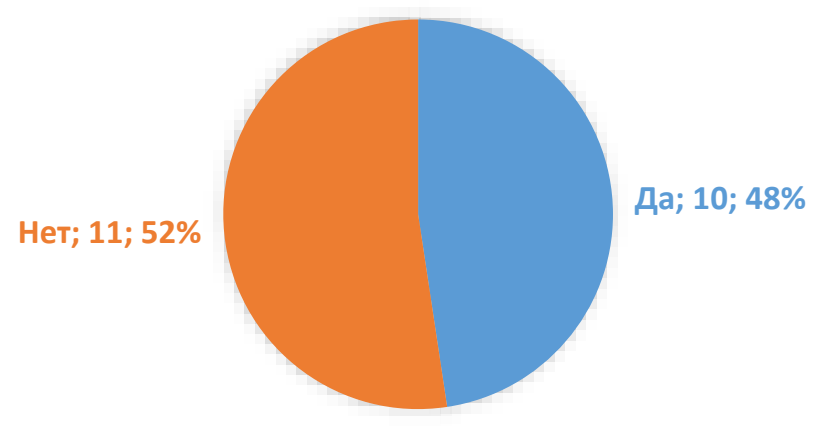

Диаграмма 4. 
Выводы. На основе результатов исследования были разработаны следующие рекомендации, учёт которых поможет субъектам бизнеса в повышение известности произведенной в регионе продукции и увеличении объема продаж:

- Провести день открытых дверей, где будет представлена продукция, произведенная в Имеретинском регионе по товарным группам и производителям бизнес субъектам;

- Провести встречи бизнес субъектов и менеджеров гостиниц с целью взаимного согласия по вопросам, связанными с предложениями и их потребностями;

- Изготовление рекламных буклетов и листов на каждую товарную категорию отдельными бизнес субъектами для создания конкурентной среды, которая даст возможность потребителю ознакомится с каждой категорией и выбрать приемлемую для него продукцию с полезными свойствами, ценой и другими показателями.

И наконец, анализ результатов исследования дает возможность сказать, что произведенная в Имерети продукция имеет потенциал повысить объем продаж не только внутри страны, но и за ее пределами. Это подтверждают данные департамента статистики Грузии об экспорте и импорте по товарным группам: по данным 2017 года экспорт живых кур составил - 1176,4 тыс. долл. США, яиц домашних кур 123,3 тыс. долл. США (2016г.), меда 15,8 тыс. долл. США, черного чая 1604,1 тыс. долл. США [2]. Если сравнить эти показатели с показателями 2015 года видно, что значительно возросли. Например, экспорт огурцов в 2015 году составил 131, 8 тыс. долл. США, что почти в 6 раз меньше показателей 2017 года.

\section{ЛИТЕРАТУРА}

1. Интернет ресурс: http://www.geostat.ge 